\title{
Интраабдоминальные инфекции и устойчивость их возбудителей к антибиотикам в хирургических стационарах г. Киева
}

\section{А. Г. Салманов ${ }^{1}$ А. Ю. Усенко ${ }^{2}$}

${ }^{1}$ Национальная медицинская академия последипломного образования имени П. Л. Шупика, г. Киев, ${ }^{2}$ Национальный институт хирургии и трансплантологии имени А. А. Шалимова НАМН Украины, г. Киев

\section{Intraabdominal infections and resistance of their causative agents towards antibiotics in surgical stationaries in the City of Kyiv}

\section{A. G. Salmanov ${ }^{1}$, A. Yu. Usenko²}

${ }^{1}$ Shupyk National Medical Academy of Postgraduate Education, Kyiv,

${ }^{2}$ Shalimov National Institute of Surgery and Transplantology, Kyiv

Реферат

Цель. Изучить клинические и микробиологические особенности интраабдоминальных инфекций (ИАИ), а также антибиотикорезистентность их возбудителей, выделенных от пациентов, госпитализированных в хирургические стационары г. Киева. Материалы и методы. Исследованы 1622 интраперитонеальных изолята, выделенных от 662 пациентов в возрасте от 22 до 84 лет, которые с бактериологически подтвержденными ИАИ с января 2014 по декабрь 2016 г. находились на лечении в хирургических отделениях 7 больниц г. Киева. Идентифицировали полученные культуры и определяли их чувствительность к 20 антибиотикам с помощью автоматизированного анализатора Vitek 2 Compact. В некоторых тестах использовали диско-диффузионный метод Кирби-Бауэpa (Kirby - Bauer). Результаты чувствительности к антибиотикам оценивали в соответствии с рекомендациями Института клинических и лабораторных стандартов США.

Результаты. Среди 662 пациентов у 468 (70,7\%) наблюдали внебольничные, у 194 (29,3\%) - внутрибольничные инфекции. Умерли 10,3\% госпитализированных больных с внебольничными и $14,4 \%$ - с внутрибольничными инфекциями. Сопутствующие заболевания и показатели тяжести чаще наблюдали при внутрибольничных инфекциях, чем при внебольничных. Тип и локализация перитонита были различными при внутрибольничных и внебольничных инфекциях. Распределение микроорганизмов в зависимости от происхождения инфекции (внебольничная и внутрибольничная) также было различным. У пациентов с внутрибольничными инфекциями наблюдали увеличение доли аэробных бактерий, в том числе Enterococcus faecalis - 34,7\% и Pseudomonas aeruginosa - 12,9\% по сравнению внебольничными инфекциями - соответственно 21,6 и $5 \%$. В то же время у пациентов с внутрибольничными инфекциями была ниже доля Escherichia coli - 52\% и штаммов стрептококков - 31\%, чем у пациентов с внебольничными инфекциями - соответственно 72 и 50\%. Среди тестируемых антибиотиков карбапенемы (имипенем и эртапенем) и амикацин были наиболее активными против Enterobacteriaceae как при внебольничных, так и при внутрибольничных инфекциях. Против P. aeruginosa амикацин, имипенем, цефтазидим и ципрофлоксацин были наиболее активными при внебольничных инфекциях, тогда как имипенем, цефепим и амикацин - при внутрибольничных. Наиболее активными против грамположительных бактерий были ванкомицин и тейкопланин как при внебольничных, так и при внутрибольничных инфекциях, включая штаммы Е. faecium. Против анаэробных бактерий наибольшую активность проявляли имипенем и эртапенем как при внебольничном, так и при внутрибольничном перитоните.

Выводы. Тактику применения антибиотиков в каждом хирургическом стационаре следует определять в зависимости от локальных данных резистентности к ним. Учитывая постоянные изменения и существенные отличия резистентности, что наблюдается в разных регионах, необходимо проводить постоянный мониторинг в каждом хирургическом стационаре и на основании полученных локальных данных разрабатывать больничный формуляр антибиотиков.

Ключевые слова: хирургия; перитонит; внутрибольничные инфекции; внебольничные инфекции; сопутствующие заболевания; смертность; патогены; антибиотикорезистентность.

Abstract

Objective. To study clinical and microbiological peculiarities of intraabdominal infections (IAI), as well as resistance towards antibiotics of their causative agents, extracted from the patients, who were admitted to surgical stationaries in the City of Kiev.

Materials and methods. There were investigated 1622 intraperitoneal isolates, which were bacteriologically confirmed as IAI and obtained from 662 patients, ageing 22-84 yrs old, who were treated in surgical departments of 7 hospitals in City of Kiev from Jan. 2014 yr till Dec. 2016 yr. Identification and determination of sensitivity of the cultures obtained towards 20 antibiotics were conducted with the help of automated analizer Vitek 2 Compact. Kirby - Bauer disc-diffusion method was applied in some tests. The sensitivity towards antibiotics results were estimated in accordance to recommendation of the Institute of clinical and laboratory standards of the USA.

Results. Among 662 patients in 468 (70.7\%) the extramural infections were observed, while in 194 (29.3\%) - nosocomial infections. Mortality index in admitted to hospital patients have constituted $10.3 \%$ - for extramural infections and $14.4 \%$ - for nosocomial. Concurrent diseases anc the severity indices were observed more frequently in nosocomial infections, than in extramural. The peritonitis type and localization were different in nosocomial and extramural infections. Distribution of microorganisms, depending on the infection origin (extramural and nosocomial) was different as well. In the patients, who suffered nosocomial infections, increase of the stationary aerobic bacteria was observed, including Enterococcus faecalis $-34.7 \%$ and Pseudomonas aeruginosa - $12.9 \%$ comparing with extramural infections $-21,6$ and $5 \%$, accordingly were observed. While in the patients, suffering nosocomial infections, the proportions of Escherichia coli $-52 \%$ and strains of streptococcus - $31 \%$, was lower, than in the patients with extramural infections - 72 and 50\%, accordingly. Among antibiotics tested, carbapenems (imipenem and ertapenem) and amicacin were mostly active against Enterobacteriaceae: both - in extramural and nosocomial infections. Against P. aeruginosa amicacin imipenem, ceftazidim have appeared mostly active in extramural infections, while imipenem, cefepim and amicacin - in nosocomial infections Vancomicin and teycoplanin were mostly active against gram-positive bacteria, both - towards nosocomial, as well as in nosocomial infections, including strains of E. faecium. Against anaerobic bacteria the largest activity was revealed by imipenem and ertapenem, in extramural as well as nosocomial peritonitis

Conclusion. The tactics for antibiotics application ought to be established in every surgical stationary, depending on local data for resistance towards them. Taking into account the constant changes and essential differences of the strains resistance, which are specific in different regions, it is necessary to conduct a constant monitoring in every surgical stationary, and, basing on the local data obtained, to elaborate the hospital formulary for antibiotics.

Keywords: surgery; peritonitis; nosocomial infections; extramural infections; concurrent diseases; mortality; pathogens; resistance towards antibiotics. 
Интраабдоминальные инфекции (ИАИ) являются актуальной проблемой современной медицины в связи с заболеваемостью и смертностью, которые они обуславливают. Среди причин хирургической заболеваемости и летальности ИАИ занимают одно из ведущих мест [1 3]. Клинически важной особенностью ИАИ, во многом определяющей неудовлетворительный прогноз, является быстрое развитие генерализованной реакции макроорганизма в ответ на инфекционный процесс, обусловленный действием бактерий эндогенного или экзогенного происхождения. В клинической практике встречаются внебольничные и внутрибольничные (послеоперационные) ИАИ.

Современные принципы лечения больных с ИАИ предусматривают использование антимикробных препаратов сразу после выявления клинических признаков заболевания. В лечении инфекций этиотропной терапии отводится важное, но не ведущее место. Как и в подавляющем большинстве других клинических ситуаций, в связи с ограниченными возможностями микробиологической диагностики антибактериальные препараты при хирургических гнойно-воспалительных инфекциях назначают эмпирически [4 - 6]. Неадекватное эмпирическое лечение несет в себе угрозу смерти больного [7].

Результатами многих исследований доказано неадекватное использование в хирургии противомикробных препаратов, которое способствует появлению и распространению резистентных микроорганизмов, что приводит к увеличению затрат на лечение [8 - 12].

Выбирая режим эмпирической терапии, как правило, ориентируются на условия возникновения (внебольничные или внутрибольничные) инфекций и наличие риска присутствия полирезистентных штаммов предполагаемых возбудителей. Риск неэффективности лечения и летального исхода значительно возрастает, если инфекции вызваны резистентными к антибиотикам микроорганизмами, особенно внутрибольничными штаммами [5, 13]. В связи с этим важно знание об основных возбудителях инфекций и их устойчивости к антибиотикам, применяемым в клинической практике.

Большинство ИАИ имеют полимикробную этиологию. Удельный вес патогенов в этиологической структуре инфекций и их антибиотикорезистентность в странах мира различаются $[4,13-16]$.

Несмотря на актуальность и клиническое значение, в Украине нет официальных данных о заболеваемости ИАИ и антибиотикорезистентности их возбудителей в стационарах страны. Очевидно, что необходимы местные данные о резистентности возбудителей ИАИ к антибиотикам, применяемым в клинической практике. В то же время в отечественной литературе этой проблеме посвящены единичные исследования, проведенные в масштабах отдельных больниц (отделений), что не дает возможности получить важную информацию об основных возбудителях инфекций и их резистентности к противомикробным препаратам в масштабах страны. Ориентироваться только на данные зарубежных исследований нельзя, даже если они достоверны, поскольку в связи со значительными различиями в политике применения антибиотиков в
Украине и других странах уровни резистентности к антибиотикам могут значительно различаться.

Цель исследования: изучение клинических и микробиологических особенностей внебольничных и внутрибольничных ИАИ, а также антибиотикорезистентности их возбудителей в хирургических стационарах г. Киева.

\section{Материалы и методы исследования}

Проведено ретроспективное исследование, в которое включены 662 пациента в возрасте от 22 до 84 лет, находившихся с января 2014 по декабрь 2016 г. на лечении в хирургических отделениях 7 больниц г. Киева с диагнозом ИАИ. Включенные в исследование больницы сопоставимы по уровню оснащенности медико-технологическим оборудованием, лабораторной базы, а также количеству выполняемых операций.

ИАИ были классифицированы как внебольничные или внутрибольничные. Послеоперационные ИАИ считали внутрибольничными. Среди сопутствующих заболеваний у пациентов с ИАИ были хроническая почечная и сердечная недостаточность, сахарный диабет, использование кортикостероидов более 1 мес, злокачественные опухоли. Принимали во внимание также данные о повторной операции в связи с инфекцией и смерти пациента. Пациента считали клинически излеченным, если у него полностью отсутствовали симптомы первоначальной инфекции.

Всего бактериологически исследованы 1622 интраперитонеальных изолята, выделенных от 662 больных с ИАИ. Идентифицировали полученные культуры и определяли их чувствительность к 20 антибиотикам (амоксициллин, амоксициллин с клавулановой кислотой, оксациллин, цефокситин, цефотаксим, цефтазидим, цефепим, тикарциллин, тикарциллин с клавулановой кислотой, пиперациллин с тазобактамом, имипенем, эртапенем, клиндамицин, гентамицин, амикацин, ванкомицин, тейкопланин, левофлоксацин, пефлоксацин, ципрофлоксацин) с помощью автоматизированного анализатора Vitek 2 Compact (производства BioMerieux, Франция). В некоторых тестах использовали диско - диффузионный метод Кирби-Бауэра (Kirby - Bauer Disk Diffusion Test). Peзультаты чувствительности к антибиотикам оценивали в соответствии с рекомендациями Института клинических и лабораторных стандартов США [17].

Для сбора данных использованы специально подготовленные таблицы, отчеты микробиологических лабораторий и другая медицинская документация. Полученные данные заносили для дальнейшего анализа в компьютерную программу WHO-NET 5.1 (Copyright1989 - 2001 WHO. All rights reserved). Формировали базу данных и проводили их статистический анализ с использованием компьютерной программы Microsoft Excel, соблюдая принципы статистического анализа, принятые в биологии и медицине. Анализировали данные с использованием методов расчета относительных и средних величин. Частоту определяли в процентах. Количественные результаты статистически обработаны общепринятыми методами вариационной и корреляционной статистики. Статистическая значимость полученных данных установлена при р <0,05. 


\section{Результаты}

Характеристика пациентов и заболевания. В исследование включено 662 пациента (женщин - 54\%, мужчин - 46\% в возрасте от 22 до 84 лет), которые с января 2014 по декабрь 2015 г. находились на лечении в хирургических отделениях 7 больниц г. Киева с диагнозом ИАИ. Из них у 468 (70,7\%) пациентов были внебольничные, у 194 (29,3\%) - внутрибольничные инфекции. В общей сложности бактериологически исследовано 1622 интраперитонеальных изолята, выделенных от 662 больных с ИАИ. Характеристика и клинический статус пациентов представлены в табл. 1, характеристика ИАИ - в табл. 2.

Сопутствующие заболевания и показатели тяжести во время диагностики чаще наблюдали при внутрибольнич- ных инфекциях по сравнению с внебольничными. Тип и локализация перитонита также различались у пациентов с внутрибольничными и внебольничными инфекциями

Предоперационная антибактериальная терапия. Противомикробное лечение в течение 7 дней до операции проведено 32 (7\%) пациентам с внебольничными инфекциями, назначали главным образом амоксициллин с клавулановой кислотой. Получали антибиотики 106 (55\%) пациентов с внутрибольничными инфекциями ( $\mathrm{p}<0,001)$, в основном амоксициллин с клавулановой кислотой $(\mathrm{n}=20)$ или пиперациллин с тазобактамом $(\mathrm{n}=22)$ либо комбинации различных противомикробных препаратов $(\mathrm{n}=64)$.

микробиологическе исследования. Транспортировали биологический материал в лабораторию не более 2 ч

\begin{tabular}{|c|c|c|c|c|c|}
\hline \multirow{3}{*}{ Параметры } & \multicolumn{4}{|c|}{ ИАИ } & \multirow{3}{*}{$p$} \\
\hline & \multicolumn{2}{|c|}{$\begin{array}{l}\text { внебольничные } \\
(\mathrm{n}=468)\end{array}$} & \multicolumn{2}{|c|}{$\begin{array}{l}\text { внутрибольничные } \\
\text { (n=194) }\end{array}$} & \\
\hline & абс. & $\%$ & абс. & $\%$ & \\
\hline \multicolumn{6}{|l|}{ Сопутствующие заболевания } \\
\hline онкологические & 54 & 11,5 & 62 & 31,9 & $<0,001$ \\
\hline сердечная недостаточность & 52 & 11,1 & 24 & 12,4 & $\mathrm{CH}$ \\
\hline сахарный диабет & 38 & 8,1 & 34 & 17,5 & $<0,05$ \\
\hline терапия кортикостероидами более 1 мес & 18 & 3,8 & 8 & 4,1 & $\mathrm{CH}$ \\
\hline хроническая почечная недостаточность & 16 & 3,4 & 21 & 10,8 & $<0,05$ \\
\hline \multicolumn{6}{|l|}{ Количество сопутствующих заболеваний } \\
\hline нет & 326 & 69,7 & 90 & 46,4 & \\
\hline 1 & 106 & 22,6 & 70 & 36,1 & $<0,001$ \\
\hline 2 и более & 36 & 7,7 & 34 & 17,5 & \\
\hline Оценка по шкале ASA класс 1 или 2 & 254 & 54,3 & 64 & 33,0 & $<0,001$ \\
\hline $\begin{array}{l}\text { ASA - шкала оценки физиче } \\
\text { статистически незначима (т }\end{array}$ & $\begin{array}{l}\text { тоян } \\
\text { бл. } 2\end{array}$ & $A M$ & общ & :иол & оазница \\
\hline
\end{tabular}

\begin{tabular}{|c|c|c|c|c|c|}
\hline \multirow{3}{*}{ Параметры } & \multicolumn{4}{|c|}{ ИАИ } & \multirow{3}{*}{$\mathrm{P}$} \\
\hline & \multicolumn{2}{|c|}{$\begin{array}{c}\text { внебольничные } \\
(n=468)\end{array}$} & \multicolumn{2}{|c|}{$\begin{array}{c}\text { внутрибольничные } \\
(n=194)\end{array}$} & \\
\hline & абс. & $\%$ & абс. & $\%$ & \\
\hline \multicolumn{6}{|l|}{ Тип перитонита } \\
\hline распространенный & 164 & 35,0 & 106 & 54,6 & $<0,001$ \\
\hline локализованный & 304 & 64,9 & 88 & 45,4 & $<0,001$ \\
\hline гнойный & 348 & 74,4 & 140 & 72,2 & $\mathrm{CH}$ \\
\hline каловый & 106 & 22,6 & 46 & 23,7 & $\mathrm{CH}$ \\
\hline \multicolumn{6}{|l|}{ Локализация повреждений } \\
\hline ниже брыжейки поперечной ободочной кишки & 332 & 70,9 & 138 & 71,1 & $\mathrm{CH}$ \\
\hline червеобразный отросток & 160 & 34,2 & 14 & 7,2 & $<0,001$ \\
\hline толстая кишка & 138 & 29,5 & 82 & 42,3 & $<0,05$ \\
\hline дивертикулит & 44 & 9,4 & 12 & 6,2 & $\mathrm{CH}$ \\
\hline злокачественный рак & 36 & 7,7 & 28 & 14,4 & $\mathrm{CH}$ \\
\hline тонкая кишка & 56 & 12,0 & 46 & 23,7 & $<0,01$ \\
\hline желчевыводящие пути & 92 & 19,7 & 22 & 11,3 & $\mathrm{CH}$ \\
\hline желудок и двенадцатиперстная кишка & 32 & 6,8 & 26 & 13,4 & $\mathrm{CH}$ \\
\hline \multicolumn{6}{|l|}{ Причина послеоперационных инфекций } \\
\hline перфорация & - & - & 56 & 28,9 & - \\
\hline расхождение швов & - & - & 58 & 29,9 & - \\
\hline не определена & - & - & 72 & 37,1 & - \\
\hline
\end{tabular}




\section{Таблица 3. Микроорганизмы, выделенные из перитонеальной жидкости при внебольничных} и внутрибольничных ИАИ

\begin{tabular}{|c|c|c|c|c|c|}
\hline \multirow{3}{*}{ Микроорганизмы } & \multicolumn{4}{|c|}{ ИАИ } & \multirow{3}{*}{$p$} \\
\hline & \multicolumn{2}{|c|}{ внебольничные } & \multicolumn{2}{|c|}{ внутрибольничные } & \\
\hline & абс. & $\%$ & абс. & $\%$ & \\
\hline Аэробы & 740 & 71,6 & 438 & 75,8 & $<0,05$ \\
\hline Грамотрицательные бактерии & 444 & 42,9 & 248 & 42,9 & $\mathrm{CH}$ \\
\hline Escherichia coli & 318 & 71,6 & 130 & 52,4 & $<0,001$ \\
\hline Klebsiella spp. & 30 & 6,8 & 26 & 10,5 & $\mathrm{CH}$ \\
\hline Enterobacter spp. & 56 & 12,6 & 46 & 18,5 & $<0,05$ \\
\hline Proteus mirabilis & 15 & 3,4 & 12 & 4,8 & $\mathrm{CH}$ \\
\hline Pseudomonas aeruginosa & 22 & 5,0 & 32 & 12,9 & $<0,01$ \\
\hline Serratia marcescens & 3 & 0,7 & 2 & 0,8 & $\mathrm{CH}$ \\
\hline Грамположительные кокки & 296 & 28,6 & 190 & 32,9 & $\mathrm{CH}$ \\
\hline Enterococcus faecalis & 64 & 21,6 & 66 & 34,7 & $<0,05$ \\
\hline Enterococcus faecium & 32 & 10,8 & 16 & 8,4 & $\mathrm{CH}$ \\
\hline Enterococcus (другие) & 26 & 8,8 & 26 & 13,7 & $\mathrm{CH}$ \\
\hline Streptococcus spp. & 148 & 50,1 & 58 & 30,5 & $<0,01$ \\
\hline Staphylococcus aureus & 22 & 7,4 & 12 & 6,3 & $\mathrm{CH}$ \\
\hline Staphylococci coagulase-negative & 12 & 4,1 & 16 & 8,2 & $\mathrm{CH}$ \\
\hline другие & 74 & 25,1 & 26 & 13,7 & $\mathrm{CH}$ \\
\hline Анаэробы & 266 & 25,7 & 114 & 19,7 & $\mathrm{CH}$ \\
\hline Anaerobes spp. & 80 & 30,1 & 34 & 29,8 & $\mathrm{CH}$ \\
\hline Bacteroides spp. & 186 & 69,9 & 80 & 70,2 & $\mathrm{CH}$ \\
\hline Грибы & 38 & 3,7 & 26 & $(4,5$ & $\mathrm{CH}$ \\
\hline Candida albicans & 28 & 73,7 & 16 & 61,5 & $\mathrm{CH}$ \\
\hline другие & 10 & 26,3 & 10 & 38,5 & $\mathrm{CH}$ \\
\hline Всего ... & 1044 & 100,0 & 578 & 100,0 & \\
\hline
\end{tabular}

как в наблюдениях внебольничных, так и в наблюдениях внутрибольничных инфекций. Положительные культуры крови были зарегистрированы у 26 (5,6\%) пациентов с внебольничными и 16 (8,2\%) - с внутрибольничными инфекциями. Из перитонеальной жидкости в каждом образце биологического материала выделены 3 и более штаммов в 34,2\% наблюдений внебольничных и в 54,8\% наблюдений внутрибольничных инфекций ( $<$ 0,001). Всего выделено 1622 штамма микроорганизмов. Удельный вес отдельных микроорганизмов в общей структуре возбудителей ИАИ в зависимости от того, внебольничные инфекции или внутрибольничные, различался (табл.3).

Из данных, приведенных в табл. 3, видно, что у пациентов с внутрибольничными инфекциями по сравнению с пациентами с внебольничными инфекциями в этиологической структуре ИАИ доля аэробных бактерий выше ( $\mathrm{p}<0,05)$, в том числе доля Enterococcus faecalis составила соответственно 34,7 и 21,6\% (p < 0,05), а штаммов Pseudomonas aeruginosa - соответственно 12,9 и 5\% (p < 0,01). В то же время у пациентов с внутрибольничными инфекциями доля Escherichia coli была ниже - 52\%, чем у пациентов с внебольничными инфекциями - 72\% (р < 0,001), а штаммов стрептококков - соответственно 31 и $50 \%(\mathrm{p}<0,01)$.

С учетом предыдущей антибактериальной терапии, мы не наблюдали никаких изменений в типе или пропорции выделенных микроорганизмов у пациентов с внебольничными и внутрибольничными инфекциями.
Чувствительность кантибиотикам. Среди тестируемых антимикробных препаратов карбапенемы (имипенем и эртапенем) и амикацин были наиболее активными in vitro против Enterobacteriaceае как при внебольничных, так и при внутрибольничных инфекциях (табл.4). Высокую активность в отношении E.coli и Enterobacter spp. как при внебольничных, так и при внутрибольничных инфекциях проявили имипенем, эртапенем и левофлоксацин. Штаммы Klebsiella spp. и P.mirabilis были высоко восприимчивы к большинству тестируемых антибиотиков как при внебольничных, так и при внутрибольничных инфекциях. Против Pseudomonas aeruginosa при внебольничных инфекциях были наиболее активными амикацин, имипенем, цефтазидим и ципрофлоксацин, при внутрибольничных - имипенем, цефепим и амикацин.

От больных с внебольничными ИАИ не были выделены метициллин - резистентрые штаммы Staphylococcus aureus (MRSA) и ванкомицин - резистентные штаммы әнтерококков (VRE). От пациентов с внутрибольничными инфекциями выделены 4 штамма MRSA, что составило 11,8\% от всех тестированных штаммов Staphylococcus aureus, и 4 (2,9\%) штамма VRE. В отношении Staphylococcus aureus при внебольничных инфекциях наиболее активными были эртапенем, гентамицин, пефлоксацин, ванкомицин, оксациллин, цефокситин, при внутрибольничных гентамицин, пефлоксацин, ванкомицин и тейкопланин.

Ванкомицин и тейкопланин были наиболее активными in vitro как при внебольничных, так и при внутрибольнич- 
ных инфекциях, вызванных Enterococcus faecium. Высокую активность в отношении Enterococcus faecalis как при внебольничных, так и при внутрибольничных инфекциях проявили амоксициллин, тейкопланин и ванкомицин.

Против анаэробных бактерий наиболее активными агентами были два карбапенема - имипенем и эртапенем как при внебольничном, так и при внутрибольничном перитоните. Анализ данных предыдущей антибактериальной терапии и тестирования на чувствительность не выявил какого-либо конкретного механизма резистентности.

Антибиотикотерапия. Адекватная антибиотикотерапия была проведена в отношении патогенов, выделенных после операции у 63,2\% пациентов с внебольничными и 64,1\% - с внутрибольничными инфекциями. Клинический статус (сопутствующие заболевания или признаки тяжести состояния), этиология перитонита существенно не влияли на адекватность выбора антибиотика для лечения, за исключением наличия повреждений желчевыводящих путей при внебольничных инфекциях. Эмпирическая антибиотикотерапия была адекватна только у 15 $(33,1 \%)$ больных с повреждениями желчевыводящих путей по сравнению с 81,2\% больных без таких повреждений $(\mathrm{p}<0,001)$. Неадекватность антибиотикотерапии отмечена в отношении Escherichia coli $(n=22)$, Enterobacter spp. $(n=10)$ и Klebsiella spp. $(n=20)$, а также Enterococcus faecalis $(n=8)$ и Enterococcus faecium $(n=12)$.

Повторную операцию выполнили у 14 (3,0\%) пациентов с внебольничными и у 30 (15,4\%) - с внутрибольничными инфекциями $(\mathrm{p}<0,001)$.

Летальность при интраабдоминальных инфекциях. Умерли 76 (11,5\%) госпитализированных больных, в том числе 48 (10,3\%) - с внебольничными и $28(14,4 \%)$ - с внутрибольничными инфекциями.

Анализ данных показал, что между пациентами с внебольничными и внутрибольничными инфекциями, по- лучившими адекватную (11,5\%) и неадекватную $(11,5 \%)$ антибиотикотерапию, а также между пациентами, которым выполняли повторную операцию $(10,4 \%)$ и которым ее не выполняли (14,2\%), не было статистически значимой разницы в уровне смертности.

Установлено различие в уровне смертности пациентов в зависимости от этиологического агента при внебольничном перитоните. Смертность при внебольничном и внутрибольничном перитоните с положительными культурами энтерококков составила соответственно $20,0$ и 8,1\% ( $=0,003)$. При внутрибольничном перитоните достоверной разницы между смертностью и выживаемостью, связанными с разными видами бактерий, не наблюдали.

Наличие одного или нескольких сопутствующих заболеваний, нескольких критериев тяжести инфекции, генерализованного перитонита, а также энтерококков в качестве этиологического агента ИАИ оказывало статистически значимое влияние на уровень смертности пациентов. В то же время адекватность антибактериальной терапии значительно не влияла на уровень смертности пациентов. При многофакторном анализе наличие одного или более сопутствующих заболеваний ( $\mathrm{p}=0,007)$, одного или нескольких показателей тяжести ( $<<0,001)$, а также генерализованного перитонита ( $=0,006)$ служило прогностическим критерием смерти пациента.

\section{Обсуждение}

В ходе ретроспективного исследования анализировали микробиологические и клинические данные пациентов с внебольничными и внутрибольничными ИАИ. Мы предполагаем, что это описательное исследование отражает «реальные» условия. Основными результатами нашего исследования являются разнообразие исследованных микроорганизмов, выделенных от пациентов с вну-

\begin{tabular}{|c|c|c|c|c|c|c|c|c|c|c|}
\hline \multirow[t]{4}{*}{ Таблица 4.} & \multicolumn{10}{|c|}{$\begin{array}{l}\text { Чувствительность к антибиотикам аэробных грамотрицательных бактерий (\% восприимчивых), } \\
\text { выделенных у пациентов с внебольничными (1) и внутрибольничными (2) ИАИ }\end{array}$} \\
\hline & \multicolumn{10}{|c|}{ Бактерии } \\
\hline & \multicolumn{2}{|c|}{$\begin{array}{l}\text { E. coli } \\
(n=23)\end{array}$} & \multicolumn{2}{|c|}{$\begin{array}{l}\text { Klebsiella spp. } \\
\quad(n=27)\end{array}$} & \multicolumn{2}{|c|}{$\begin{array}{l}\text { Enterobacter spp. } \\
\qquad(n=56)\end{array}$} & \multicolumn{2}{|c|}{$\begin{array}{l}\text { P. mirabilis } \\
(n=16)\end{array}$} & \multicolumn{2}{|c|}{$\begin{array}{l}\text { P. aeruginosa } \\
\quad(n=31)\end{array}$} \\
\hline & 1 & 2 & 1 & 2 & 1 & 2 & 1 & 2 & 1 & 2 \\
\hline Амоксициллин & 65,1 & 45,1 & HT & HT & HT & HT & 70,8 & 50,0 & HT & HT \\
\hline $\begin{array}{l}\text { Амоксициллин } \\
\text { с клавулановой } \\
\text { кислотой }\end{array}$ & 77,9 & 57,8 & 79,8 & 85,1 & 15,2 & 18 & 86,1 & 74,3 & HT & HT \\
\hline Тикарциллин & 68,8 & 48,1 & HT & HT & 92,1 & 64,0 & 71,2 & 50,3 & 81,3 & 60,2 \\
\hline $\begin{array}{l}\text { Пиперациллин } \\
\text { с тазобактамом }\end{array}$ & 97,2 & 86,3 & 100,0 & 92,3 & 95,9 & 64,1 & 100,0 & 100,0 & 87,4 & 81,1 \\
\hline Имипенем & 100,0 & 100,0 & 100,0 & 100,0 & 100,0 & 100,0 & 100,0 & 100,0 & 100,0 & 94,3 \\
\hline Эртапенем & 100,0 & 100,0 & 100,0 & 100,0 & 100,0 & 100,0 & 100,0 & 100,0 & HT & HT \\
\hline Цифотаксим & 98,8 & 90,1 & 100,0 & 100,0 & 96,1 & 61,2 & 100,0 & 100,0 & HT & HT \\
\hline Цефтазидим & 98,9 & 89,6 & 100,0 & 100,0 & 96,0 & 64,1 & 100,0 & 100,0 & 100,0 & 86,9 \\
\hline Цефепим & 97,9 & 96,1 & 100,0 & 100,0 & 100,0 & 90,0 & 100,0 & 100,0 & 100,0 & 88,7 \\
\hline Гентамицин & 99,0 & 89,1 & 100,0 & 100,0 & 100,0 & 91,2 & 100,0 & 100,0 & 69,2 & 53,1 \\
\hline Амикацин & 98,9 & 100,0 & 100,0 & 100,0 & 100,0 & 91,1 & 100,0 & 100,0 & 100,0 & 100,0 \\
\hline Ципрофлоксацин & 94,8 & 86,8 & 100,0 & 100,0 & 100,0 & 100 & 100,0 & 78,1 & 100,0 & 81,3 \\
\hline Левофлоксацин & 100,0 & 66,9 & HT & 100,0 & 100,0 & 66,8 & $\mathrm{HT}$ & HT & HT & HT \\
\hline
\end{tabular}


трибольничными инфекциями, и снижение их чувствительности к антимикробным препаратам.

В последние годы опубликованы результаты исследований, посвященных тестированию чувствительности возбудителей ИАИ, которыми внесен важный вклад в изучение кишечных микроорганизмов [18 - 22]. По данным ряда исследований в перитонеальных изолятах доля штаммов Е. coli как при внебольничных, так и при внутрибольничных ИАИ составила 50\% [18, 23]. Приведены различные данные о частоте развития внутрибольничных и внебольничных ИАИ - соответственно 49 и 51\%, 31 и 69\%, 53 и 47\% [20 22]. В нашем исследовании частота развития внутрибольничных ИАИ составила 29,3\%, внебольничных - 70,7\%.

Полученные нами результаты подтвердили клинические и микробиологические различия между внебольничным и внутрибольничным перитонитом, которые наблюдали и другие исследователи [20, 21, 24]. У пациентов с внутрибольничными инфекциями было, как и ожидалось, больше сопутствующих заболеваний и показателей тяжести. Наши данные об источнике инфекции, вовлеченных органах, типе перитонита отличаются от данных, имеющихся в доступной литературе, как при внебольничных, так и при внутрибольничных инфекциях [20 - 22, 24, 25].

Бактериальный спектр штаммов, выделенных от пациентов с внебольничным перитонитом, сопоставим с данными в опубликованных ранее отчетах, в которых E. coli, Streptococcus spp. и Bacteroides fragilis приведены как наиболее часто выделяемые микроорганизмы [20, 21, 25]. Выявленное нами значительное количество штаммов E. coli, устойчивых к амоксициллину и амоксициллину с клавулановой кислотой, соответствует литературным данным [21].

В нашем исследовании энтерококки в общей структуре этиологических агентов составили 11,8\% изолятов при внебольничных и 18,7\% - при внутрибольничных инфекциях. Литературные данные в отношении этиологической роли энтерококков в развитии внебольничного и внутрибольничного перитонита различаются. Исследователи отмечают увеличение этиологической роли энтерококков при внутрибольничных инфекциях по сравнению с внебольничными [21, 22, 24]. В то же время удельный вес энтерококков в общей структуре этиологических агентов перитонита при внутрибольничных инфекциях оказался низким по сравнению с данными исследований внутрибольничных инфекций [26].

Низкий уровень ванкомицин-резистентных энтерококков в больницах г. Киева был подтвержден их отсутствием во время нашего исследования. В литературе есть сообщения об увеличении заболеваемости перитонитом, вызванным энтерококками, но о повышенной смертности, связанной только с энтерококками, сообщается в двух работах $[21,26]$. Смертность среди исследованных нами пациентов с внебольничными инфекциями составила 10,3\%. При внутрибольничном перитоните достоверной разницы между смертностью и выживаемостью, связанными с разными видами бактерий, не наблюдали.

В нашем исследовании частота неадекватной эмпирической антибактериальной терапии была одинаковой как при внебольничных, так и при внутрибольничных ИАИ 11,5\%. По данным разных авторов, частота неадекватной к этиологическому агенту антибиотикотерапии при внебольничных ИАИ колеблется от 13 [26] до 36\% [24]. В других исследованиях этот показатель составляет 35 - 40\% $[20,24]$. По данным литературы неадекватная антибактериальная терапия увеличивает смертность больных от инфекции [26 - 28]. Мы не получили данных о том, что неадекватная эмпирическая антибиотикотерапия стала существенной причиной повышенной смертности пациентов. Связь между неадекватным использованием антибиотиков и повышенной смертностью пациентов не была доказана и в других исследованиях, посвященных внебольничным и внутрибольничным инфекциям [20, 21, 24]. Полученные нами результаты дают основание утверждать, что риск, связанный с неадекватной эмпирической терапией антибиотиками, остается важным у больных с внутрибольничным перитонитом, и, вероятно, он более опасен для жизни, чем чрезмерное эмпирическое лечение.

Смертность пациентов с перитонитом в нашем исследовании соответствовала данным, опубликованным в литературе, посвященной внебольничным инфекциям, но была низкой для послеоперационных внутрибольничных инфекций. Есть сообщение о том, что умерли от осложнений 9\% пациентов с внебольничным перитонитом и 39\% пациентов с внутрибольничным перитонитом [20]. По данным других авторов, смертность пациентов в отделении реанимации и интенсивной терапии составила $24 \%$ - при внебольничном перитоните и 28\% - при внутрибольничном [24]. Сопоставимый показатель смертности пациентов с внебольничным и внутрибольничным перитонитом получили и другие исследователи - 25\% [21]. В нашем исследовании смертность пациентов составила 11,5\%, в том числе 10,3\% - при внебольничных и 14,4\% при внутрибольничных инфекциях.

Ограничение в исследовании. Данное исследование имеет определенное ограничение, поскольку в него включено незначительное количество больниц. Результаты нашего исследования с участием этих больниц могут не совпадать с данными других медицинских учреждений Украины. Следует также отметить отсутствие централизованного микробиологического анализа штаммов в контрольной лаборатории, что позволило бы получить полную доступность данных о их восприимчивости. Однако все микробиологические лаборатории исследованных больниц следуют тем же принципам, которые рекомендованы Институтом клинических и лабораторных стандартов США и утверждены Министерством здравоохранения Украины. Значение результатов тестирования на восприимчивость, полученных в исследованиях с включением менее 30 микроорганизмов, всегда трудно интерпретировать. Однако при наличии ограниченных данных для антибиотиков и бактерий, что имеет место для ИАИ, некоторые авторы сообщают о результатах даже при исследовании небольшого количества штаммов. В исследовании ответ на лечение мы не контролировали, что является слабостью в изучении полимикробной инфекции, когда не все изолированные микроорганизмы ответственны за инфекцию. Кроме того, адекватность лечения трудно установить, поскольку результаты хирургического лечения не оценивали. 
Перспективы дальнейиих исследований. Несмотря на ограничение в исследовании, мы предполагаем, что наши результаты могут быть полезными для врачей. Собранная информация представляет собой первый шаг к проведению дальнейших исследований в отношении резистентности к противомикробным препаратам среди патогенов, выделенных от пациентов с ИАИ.

\section{Выводы}

1. ИАИ являются актуальной проблемой современной хирургии. Смертность от ИАИ составляет в среднем 11,5\%, в том числе 10,3\% - среди пациентов с внебольничными и 14,4\% - среди пациентов с внутрибольничными инфекциями. Наличие нескольких сопутствующих заболеваний и показателей тяжести состояния пациента, генерализованного перитонита, а также энтерококков в качестве этиологического агента ИАИ оказывает значительное влияние на смертность.

2. В лечении ИАИ этиотропной терапии отводится важное, но не ведущее место. Выбирая режим эмпирической терапии, следует ориентироваться на условия возникновения (внебольничная или внутрибольничная) инфекции и наличие риска присутствия полирезистентных штаммов предполагаемых возбудителей. В связи с этим важно знание об основных возбудителях инфекций и их устойчивости к антибиотикам, применяемым в клинической практике. Тактику применения антибиотиков в каждом хирургическом стационаре следует определять в зависимости от локальных данных резистентности к ним.

3. Учитывая постоянные изменения и существенные Отличия резистентности возбудителей ИАИ, что наблюдается в разных регионах, необходимо проводить постоянный мониторинг в каждом хирургическом стационаре и на основании полученных локальных данных разрабатывать больничный формуляр антибиотиков.

\section{Благодарность}

Авторы выражают благодарность руководителям больниц, которые принимали участие в исследовании, и Всеукраинской ассоциации инфекционного контроля и антимикробной резистентности за помощь в сборе данных для исследования.

\section{References}

1. Montravers P, Lepape A, Dubreuil L, Gauzit R, Pean Y, Benchimol D, Dupont H. Clinical and microbiological profiles of community-acquired and nosocomial intra-abdominal infections: results of the French prospective, observational EBIIA study. J Antimicrob Chemother. 2009 Apr; 63(4):785-94. doi: 10.1093/jac/dkp005.

2.Guyatt G, Gutterman D, Baumann MH, Addrizzo-Harris D, Hylek EM, Phillips B, et al. Grading strength of recommendations and quality of evidence in clinical guidelines: report from an American College of Chest Physicians task force. Chest. 2006;129:174-81. doi: 10.1378/ chest.129.1.174.

3. Sartelli M, Abu-Zidan FM, Catena F, Griffiths EA, Di Saverio S, Coimbra R, et al. Global validation of the WSES Sepsis Severity Score for patients with complicated intraabdominal infections: a prospective multicenter study (WISS Study) World J Emerg Surg. 2015;10:61. doi: 10.1186/s13017-015-0055-0.

4. Salmanov AG, Vdovychenko YuP, Nychytailo MYu, Andriuschenko DV, Verner OM. Incidence of Surgical Site Infections and Antimicrobial Resistance their Pathogens in Ukraine. International Journal of Antibiot- ics and Probiotics. 2018 Mar; 2(1):18-29. doi: https://doi.org/10.31405/ ijap.2-1.18.02.

5. Sartelli M, Catena F, Abu-Zidan FM, Ansaloni L, Biffl WL, Boermeester MA, et al. Management of intra-abdominal infections: recommendations by the WSES 2016 consensus conference. World J Emerg Surg. 2017 May 4;12:22. doi: 10.1186/s13017-017-0132-7.

6. Paul M, Shani V, Muchtar E, Kariv G, Robenshtok E, Leibovici L. Systematic review and meta-analysis of the efficacy of appropriate empiric antibiotic therapy for sepsis. Antimicrob Agents Chemother 2010;54:4851-63.

7. Bodmann KF. Complicated intra-abdominal infections: pathogens, resistance. Recommendations of the Infectliga on antbiotic therapy. Chirurg. 2010 Jan;81(1):38-49. doi: 10.1007/s00104-009-1822-9. [Article in German].

8. Mazeh H, Mizrahi I, Dior U, Simanovsky N, Shapiro M, Freund HR, et al. Role of antibiotic therapy in mild acute calculus cholecystitis: a prospective randomized controlled trial. World J Surg. 2012;36:1750 9. doi: 10.1007/s00268-012-1572-6.

9. Regimbeau JM, Fuks D, Pautrat K, Mauvais F, Haccart V, Msika S, et al. Effect of postoperative antibiotic administration on postoperative infection following cholecystectomy for acute calculous cholecystitis: a randomized clinical trial. JAMA. 2014;312:145-54. doi: 10.1001/ jama.2014.7586.

10. Sawyer RG, Claridge JA, Nathens AB, Rotstein OD, Duane TM, Evans HL, et al. Trial of short-course antimicrobial therapy for intraabdominal infection. N Engl J Med. 2015;372:1996-2005. doi: 10.1056/ NEJMoa1411162.

11. Blot S, De Waele JJ, Vogelaers D. Essentials for selecting antimicrobial therapy for intra-abdominal infections. Drugs. 2012;72:17-32. doi: 10.2165/11599800-000000000-00000.

12. Mishra SP, Tiwary SK, Mishra M, Gupta SK. An introduction of tertiary peritonitis. J Emerg Trauma Shock. 2014;7:121-3. doi: 10.4103/09742700.136872.]

13. Sartelli M, Catena F, di Saverio $\mathrm{S}$, Ansaloni L, Coccolini F, Tranà C, Kirkby-Bott J. The Challenge of Antimicrobial Resistance in Managing Intra-Abdominal Infections. Surg Infect (Larchmt). 2015 Jun;16(3):21320. doi: 10.1089/sur.2013.262.

14. Salmanov AG. Antimicrobial resistance and healthcare-associated infections in Ukraine. Epidemiological report of the multicenter study (2010-2014). Kyiv: AgrarMediaGroup; 2015. 452 p. [In Ukrainian].

15. European Centre for Disease Prevention and Control. Surveillance of antimicrobial resistance in Europe 2016. Annual Report of the European Antimicrobial Resistance Surveillance Network (EARS-Net). Stockholm: ECDC; 2017. Available from: https://ecdc.europa.eu/sites/portal/ files/documents/AMR-surveillance-Europe-2016.pdf

16. World Health Organization (WHO). Antimicrobial resistance: global report on surveillance 2014. WHO: Geneva; 2014. Available from: http:// apps.who.int/iris/bitstream/10665/112642/1/9789241564748_eng.pdf .

17. Clinical and Laboratory Standards Institute. Performance Standards for Antimicrobial Susceptibility Testing: Eighteenth Informational Supplement M100-S18. Wayne, PA, USA: CLSI; 2008.

18. Paterson DL, Rossi F, Baquero F, Hsueh PR, Woods GL, Satishchandran V, et al. In vitro susceptibilities of aerobic and facultative Gramnegative bacilli isolated from patients with intra-abdominal infections worldwide: the 2003 Study for Monitoring Antimicrobial Resistance Trends (SMART). J Antimicrob Chemother. 2005 Jun;55(6):965-73. doi: 10.1093/jac/dki117.

19. Rossi F, Baquero F, Hsueh PR, Paterson DL, Bochicchio GV, Snyder $\mathrm{TA}$, et al. In vitro susceptibilities of aerobic and facultatively anaerobic Gram-negative bacilli isolated from patients with intra-abdominal infections worldwide: 2004 results from SMART (Study for Monitoring Antimicrobial Resistance Trends). J Antimicrob Chemother. 2006 Jul;58(1):205-10. doi: 10.1093/jac/dk1199.

20. Roehrborn A, Thomas L, Potreck O, Ebener C, Ohmann C, Goretzki PE, Röher HD. The microbiology of postoperative peritonitis. Clin Infect Dis. 2001 Nov 1;33(9):1513-9. doi: 10.1086/323333.

21. Sotto A, Lefrant JY, Fabbro-Peray P, Muller L, Tafuri J, Navarro F, et al. Evaluation of antimicrobial therapy management of 120 consecutive patients with secondary peritonitis. J Antimicrob Chemother. 2002 Oct;50(4):569-76. PMID: 12356803.

22. Seguin P, Laviolle B, Chanavaz C, Donnio PY, Gautier-Lerestif AL, Campion JP, Mallédant Y. Factors associated with multidrug-resis- 
tant bacteria in secondary peritonitis: impact on antibiotic therapy. Clin Microbiol Infect. 2006 Oct;12(10):980-5. doi: 10.1111/j.14690691.2006.01507.x.

23. Baquero F, Hsueh PR, Paterson DL, Rossi F, Bochicchio GV, Gallagher $\mathrm{G}$, et al. In vitro susceptibilities of aerobic and facultatively anaerobic gram-negative bacilli isolated from patients with intra-abdominal infections worldwide: 2005 results from Study for Monitoring Antimicrobial Resistance Trends (SMART). Surg Infect (Larchmt). 2009 Apr;10(2):99-104. doi: 10.1089/sur.2008.0020.

24. Montravers P, Dupont H, Gauzit R, Veber B, Auboyer C, Blin P, Hennequin $\mathrm{C}$, Martin C. Candida as a risk factor for mortality in peritonitis. Crit Care Med. 2006 Mar;34(3):646-52. doi: 10.1097/01. CCM.0000201889.39443.D2.

25. Montravers P, Dupont H, Chalfine A, Gauzit R, Lepape A, Marmuse JP, et al. Clinical and therapeutic features of nonpostoperative nosocomial intra-abdominal infections. Ann Surg. 2004 Mar;239(3): 409-416. doi: 10.1097/01.sla.0000114214.68169.e9.
26. Sitges-Serra A, López MJ, Girvent M, Almirall S, Sancho JJ. Postoperative enterococcal infection after treatment of complicated intra-abdominal sepsis. Br J Surg. 2002 Mar;89(3):361-7. doi: 10.1046/j.00071323.2001.02023.x.

27. Dalfino L, Bruno F, Colizza S, Concia E, Novelli A, Rebecchi F, et al. Cost of care and antibiotic prescribing attitudes for community-acquired complicated intra-abdominal infections in Italy: a retrospective study. World J Emerg Surg. 2014;9:39. doi: 10.1186/1749-7922-9-39

28. Cattan P, Yin DD, Sarfati E, Lyu R, De Zelicourt M, Fagnani F. Cost of care for inpatients with community-acquired intra-abdominal infections. Eur J Clin Microbiol Infect Dis. 2002 Nov;21(11):787-93. doi: 10.1007/s10096-002-0834-x. 